\section{Should Pharmacy Technicians Provide Clinical Services or Perform Patient Care Activities in Areas without a Pharmacist?}

\section{THE "PRO" SIDE}

One priority in achieving "the vision for pharmacy" is to have both pharmacists and pharmacy technicians in all settings contributing to optimal drug therapy outcomes. ${ }^{1}$ The context for our argument that pharmacy technicians should provide clinical services and perform patient care activities in areas without a pharmacist can be derived by considering a secondary question: Would patient care be optimized through the provision of clinical services supported by pharmacy technicians? Because pharmacists are in short supply both nationally and internationally, ${ }^{2}$ we believe that pharmacy technicians must perform patient care activities in areas without a pharmacist if the profession is to achieve optimal use of the pharmacy workforce and meet increasing expectations for clinical pharmacy.

\section{Optimization of the Pharmacy Workforce}

Pharmacists are well trained to focus on and lead medication management activities that will help to optimize patient care. Increasingly, however, pharmacists are having to prioritize their services to the sickest patients and those with complex or high-risk medication regimens. As a result, other patients who could benefit from clinical pharmacy services do not receive them. As attempts are made to provide clinical pharmacy services to all patients, competent pharmacy technicians can contribute important elements of these services and facilitate a more desirable pharmaceutical care model. For example, under the direction of a pharmacist, even at a distance, pharmacy technicians educated and trained in the provision of specific clinical services can safely and effectively provide elements of high-quality clinical services. ${ }^{3}$ In addition, a pharmacy technician could oversee certain patient care tasks, such as obtaining medication histories and tracking the results of laboratory tests, which would allow pharmacists to focus on the challenges associated with multidisciplinary collaborative practice. Supporting practice change in this manner will have an additional benefit for the workforce, because technicians will undoubtedly find these opportunities professionally rewarding.

\section{Competencies and Training}

Proposals to have pharmacy technicians provide clinical services may raise questions about their competency to do so. However, we believe that nationally established, standardized educational expectations and the introduction of rigorous entryto-practice criteria address these questions. Moreover, within its definition of clinical pharmacy, the American College of Clinical Pharmacy describes the patient care role, contending that, for pharmacists to practice effectively, it must be realized that "they don't just provide clinical services". ${ }^{4}$ Some of the competencies outlined to support this role are technical or clerical in nature, such as the collection of patient-specific data. ${ }^{5}$ Pharmacy technicians' knowledge, skills, and abilities are ideally suited to support the technical aspects of these patient care activities. ${ }^{6}$ Indeed, their training prepares them to collaborate effectively with pharmacists and other members of the health care team. Pharmacy technicians are taught to use their knowledge of pharmacology, therapeutics, and common medical conditions to alert pharmacists of therapeutic issues. Depending on the anticipated extent of their independent provision of clinical services, pharmacy technicians may need additional focused training to support the practical application of knowledge coupled with basic clinical skills. Continuing education or workplace training may satisfy the need for this focused learning.

\section{Evidence}

With these issues in mind, a recent study examined the direction of on-site pharmacy technicians by pharmacists at a distance. ${ }^{3}$ The authors found that the use of on-site pharmacy technicians led to an increase in the number of clinical interventions along with a decrease in the amount of pharmacist time required to provide these clinical interventions. ${ }^{3}$ The use of clinical alerts or trigger mechanisms based on criteria predetermined by pharmacists allows pharmacy technicians to capitalize on task orientation when they are providing clinical services. Focused tasks such as collection or dissemination of data, triage and screening of patients, and provision of discharge support are examples of clinical services that, depending on the practice setting and expectations, may be adapted for performance by pharmacy technicians. Because this is a new area for pharmacy technicians, evidence is still evolving to support this role. ${ }^{3,8,9}$

\section{Conclusions}

With expansion of roles and optimization of the workforce, pharmacy technicians are becoming more autonomous and are taking on more responsibility for pharmacy services. The implications of various policy proposals by provincial regulatory bodies support expansion of pharmacy technicians' roles, including development of clinical pharmacy activities. Under these policies, pharmacists will have greater authority to delegate and will be able to take advantage of decreasing supervision requirements, which will in turn allow for more indirect or general direction of pharmacy technicians. To realize the benefits of refined practice standards, innovative opportunities to ensure that pharmacy technicians work to their full scope of practice must be consid- 
ered. Empowering pharmacy technicians to focus on the details of selected clinical services will allow for more effective delivery of overall patient care than pharmacists alone can provide. More importantly, this particular expanded role for pharmacy technicians can be seen as the impetus for pharmacists to concentrate on resourceful, patient-focused clinical practice.

As stated in a recent international publication on developing the pharmacy profession, ${ }^{10}$

While change may generate potential threats, it can also open up immense opportunities. The pharmacy profession has a responsibility to identify new opportunities for pharmacy practice in a changing health sector context, to assess and to test them, and to demonstrate their ability to implement them successfully.

\section{References}

1. Task Force on a Blueprint for Pharmacy. Blueprint for pharmacy: implementation plan. Ottawa (ON): Canadian Pharmacists Association; 2009 [cited 2010 May 20]. Available from: www.pharmacists.ca/content/about_ cpha/whats_happening/cpha_in_action/pdf/BlueprintImplementationPlan.pdf

2. Management Committee. Moving forward: pharmacy human resources for the future. Final report. Ottawa (ON): Canadian Pharmacists Association; 2008 [cited 2010 May 20]. Available from: www.pharmacygateway.ca/ microsite/expandyourscope/pdfs/moving-forward.pdf

3. Totton JS, Hunt P, Pritchard K. Joint-effort clinical pharmacy services in rural hospitals. Can J Hosp Pharm 2008;61(2):133-137.

4. American College of Clinical Pharmacy. The definition of clinical pharmacy. Pharmacotherapy 2008;28(6):816-817.

5. American College of Clinical Pharmacy; Burke JM, Miller WA, Spencer AP, Crank CW, Adkins L, Bertch KE, et al. Clinical pharmacist competencies. Pharmacotherapy 2008;28(6):806-815.

6. Professional competencies for Canadian pharmacy technicians at entry to practice. Ottawa (ON): National Association of Pharmacy Regulatory Authorities; 2007 [cited 2010 May 20]. Available from: http:// napra.ca/Content_Files/Files/Professional_Competencies_for_Canadian_ Pharmacy_Technicians2007.pdf

7. Educational outcomes for pharmacy technician programs in Canada. Canadian Pharmacy Technician Educators Association; 2007 [cited 2010 May 20]. Available from: www.cptea.ca/private_pgs/Educational OutcomesMar2007.pdf

8. Koch KE, Weeks A. Clinically oriented pharmacy technicians to augment clinical services. Am J Health Syst Pharm 1998;55(13):1375-1381.

9. Lo A, Co M, Lo C, Chua D, Soltesz D. Specialized pharmacy oncology technician: experience at the Ridge Meadows Hospital. Can J Hosp Pharm 2010;63(2):138-141.

10. Wledenmayer K, Summers RS, Mackle CA, Gous AGS, Everard M. Developing pharmacy practice: a focus on patient care. Handbook - 2006 edition. Geneva (Switzerland): World Health Organization and International Pharmaceutical Federation; 2006. p. 7.

\section{Karen Horon, BScPharm}

Director

Practice and Therapeutic Standards \& Support

Teresa Hennessey, RPEBC-PT

Technical Educator

Pharmacy Services

Alberta Health Services

Edmonton, Alberta

\section{THE "CON" SIDE}

The roles of pharmacy technicians have expanded significantly because of improvements in training and the need to expand the direct patient care role of the pharmacist. ${ }^{1}$ Optimization of the pharmacist's time to concentrate on intellectual decision-making has been made possible by utilizing well-trained pharmacy technicians. ${ }^{2}$ This has led many in our profession to consider pharmacy technicians as the backbone of pharmacy. ${ }^{3}$ The debate surrounding expansion of technician roles began 40 years ago, and has, over time, evolved from consideration of centralized pharmacy roles to discussion of decentralized roles in patient-care areas., We view this discussion as a positive indicator of the progress that our profession has made in clarifying pharmacists' roles as clinicians who deliver patient-centred pharmaceutical care. Interestingly, more than half of respondents to a recent Canadian survey reported using pharmacy technicians in patient-care areas to support clinical pharmacists. ${ }^{5}$ This may indeed be a sign of progress; however, it is imperative that pharmacy technicians work within a model that is most likely to enable clinical pharmacists to realize their full scope of practice. A fully operational clinical pharmacist who performs key interventions will improve both clinical and economic outcomes. ${ }^{6}$ To achieve this goal, clinical pharmacy support technicians (CPSTs) must work as part of a collaborative clinical pharmacy model under the supervision of a clinical pharmacist who spends at least part of his or her time in the CPST's patientcare area.

\section{Working Synergistically with Clinical Pharmacists to Improve Outcomes}

Although CPSTs are not new, there are few published data describing their roles and how they affect clinically relevant outcomes. One of the best-studied roles of a CPST is that of obtaining the best possible medication history (BPMH) to facilitate medication reconciliation. Training for, implementation of, and quality assurance related to this activity can be standardized, and a CPST-obtained BPMH is reliable.? Most published studies examining BPMHs obtained by pharmacy technicians have been conducted in patient-care areas where clinical pharmacists were present at least part of the time. ${ }^{7-10}$ Supervision by a pharmacist is not necessary to correct mistakes in the medication verification process, but such supervision is required to identify and resolve drug-related problems. ${ }^{10}$ It is these interventions that will improve patient outcomes, and they can only be performed by a clinical pharmacist. ${ }^{6,11,12}$ For example, a dramatic reduction in the rate of adverse drug events was attributed to critical care pharmacists clarifying or correcting orders, providing drug information, recommending alternative therapies, and identifying drug interactions during physician rounds. ${ }^{13}$ Nonetheless, the CPST can play a vital role in facilitating the pharmacist's ability and efficiency in delivering these services. ${ }^{14}$ Perhaps a CPST could also enable the clinical pharmacist to see (and intervene in the care of) a greater number of patients each day, while maintaining the same depth, quality, and effectiveness of interventions. However, use of pharmacy technicians in patient-care areas without pharmacist coverage is an unproven 
strategy that is destined to fail in meeting the overall goal of CPST involvement in patient-care areas. Until evidence is available to support the role of CPSTs working outside a model of collaboration with the clinical pharmacist, these technicians should be deployed to patient-care areas to facilitate the pharmacist's delivery of a comprehensive package of clinical pharmacy interventions.

\section{Stakeholders' Perceptions of Clinical Pharmacy Services and Regulatory Concerns}

The perceptions of pharmacy stakeholders can assist in making decisions about changes in departmental operations and practices. ${ }^{15}$ It might be hypothesized that deployment of CPSTs to patient-care areas without a clinical pharmacist presence could significantly improve stakeholders' awareness of pharmacy services. However, many stakeholders are unaware of the full complement of clinical pharmacy services, and they might mistakenly conclude that activities performed by CPSTs represent the full catalogue of such services. Furthermore, their lack of awareness might lead them to be quite satisfied with the armamentarium and quality of CPST-delivered services. This misunderstanding could result in stakeholders' failing to support a pharmacy department's future proposal to expand clinical pharmacy services. Also, if CPST-activities are confused with clinical pharmacist activities, the perceived depth and quality of clinical pharmacy services may not be on par with what could be realized with a collaborative approach involving both CPSTs and clinical pharmacists. Furthermore, physicians, nurses, and patients might mistake CPSTs for clinical pharmacists and might ask them to perform activities outside of their skill set or knowledge base. Inability to deliver these services under pressure to do so could have a negative impact on the quality of a CPST's work life.

In addition, although professional regulation of pharmacy technicians in Canada is soon to be a reality, the current lack of regulation could present medicolegal challenges for CPSTs who are not working as part of a collaborative pharmacy team. The legality of technicians' involvement in medication reconciliation in the United States has recently been questioned, but many of the concerns that have been raised could be addressed by ensuring their deployment within a collaborative pharmacy model. ${ }^{16}$ Many US regulatory authorities permit technicians to obtain a BPMH with the proviso that they do so under the direct supervision of a pharmacist. In most cases this would be impossible to achieve without a pharmacist being physically present in the same patient-care area as the pharmacy technician. In a collaborative model, the CPST and clinical pharmacist work together to improve stakeholders' perceptions of professional pharmacy services and to clear potential legal hurdles.

\section{Optimizing Technicians' Roles within the Central Pharmacy}

Technicians' activities within the dispensary represent vital clinical support functions necessary for the existence of clinical pharmacy as we in the profession would like to see it. However, about $20 \%$ of respondents to the most recent Canadian hospital pharmacy survey reported that technicians do not perform medication order entry at their hospitals, and only two-thirds of hospitals were using centralized unit-dose systems. ${ }^{17}$ To realize the full benefit of clinical pharmacy services, we must first ensure that pharmacy technicians are practising to the full extent of their scope of practice within the centralized drug distribution system.

\section{Conclusions}

Many of the objectives of CSHP 2015 can be realized by employing CPSTs in patient-care areas. However, the manner in which CPSTs are deployed will dictate whether they are effective in helping to achieve these objectives. It would be illogical to use CPSTs in patient-care areas because of a pharmacist shortage or because it is less costly to compensate a technician than a pharmacist. CPSTs are meant to support, not replace, clinical pharmacists. Why would we spend significant amounts of time and money to train a key member of the hospital pharmacy team and then immerse them in a model where their effectiveness will be hamstrung by the absence of a pharmacist? Akin to any pharmaceutical intervention, CPSTs should be utilized in a manner that will effectively improve outcomes. The vital services that a CPST can offer in a patient-care area must be performed under the supervision of a pharmacist who is present in the same location. This model of practice will optimize the pharmacist's efficiency in delivering the full complement of clinical pharmacy services. To seize the opportunity to improve health outcomes, "we must emphasize quality over quantity, value over volume, and outcomes over process or structures" ${ }^{18}$ We should heed this wise advice before deploying pharmacy technicians to patientcare areas devoid of clinical pharmacists.

\section{References}

1. Ensom RJ, Tierney M. Expanded technician roles versus patient safety: finding the balance [editorial]. Can J Hosp Pharm 2004;57(3):145-146.

2. Francke DE. Hospital pharmacy technicians [editorial]. Drug Intell Clin Pharm 1968;2(10):259.

3. Keresztes JM. Role of pharmacy technicians in the development of clinical pharmacy. Ann Pharmacother 2006;40(11):2015-2019.

4. Frazier WM. Can professional time be better used? [editorial]. Drug Intell Clin Pharm 1970;4(11):299.

5. Bussières JF. Clinical pharmacy services. In: Babich M, Bussières JF, Hall KW, Harding J, Johnson N, Lefebvre P, et al., editors. Hospital pharmacy in Canada 2007/2008 annual report. Eli Lilly; 2008 [cited 2010 Jun 11]. p. 4-24. Available from: www.lillyhospitalsurvey.ca/ hpc2/content/2008_report/clinpharmacyserv.pdf

6. Bond CA, Raehl CL. Clinical pharmacy services, pharmacy staffing, and hospital mortality rates. Pharmacotherapy 2007;27(4):481-493.

7. Michels RD, Meisel SB. Program using pharmacy technicians to obtain medication histories. Am J Health Syst Pharm 2003;60(19):1982-1986.

8. Leung M, Jung J, Lau W, Kiaii M, Jung B. Best possible medication history for hemodialysis patients obtained by a pharmacy technician. Can J Hosp Pharm 2009;62(5):386-391.

9. Remtulla S, Brown G, Frighetto L. Best possible medication history by a pharmacy technician at a tertiary care hospital. Can J Hosp Pharm 2009;62(5):402-405.

10. van den Bemt PM, van den Broek S, van Nunen AK, Harbers JB, Lenderink AW. Medication reconciliation performed by pharmacy technicians at the time of preoperative screening. Ann Pharmacother 2009;43(5):868-874.

11. De Rijdt T, Willems L, Simoens S. Economic effects of clinical pharmacy interventions: a literature review. Am J Health Syst Pharm 2008; 65(12):1161-1172. 
12. Viktil KK, Blix HS. The impact of clinical pharmacists on drug-related problems and clinical outcomes. Basic Clin Pharmacol Toxicol 2008; 102(3):275-280.

13. Leape LL, Cullen DJ, Dempsey Clapp M, Burdick M, Demonaco HJ, Erickson JI, et al. Pharmacist participation on physician rounds and adverse drug events in the intensive care unit. JAMA 1999;282(3): 267-270. Erratum in: JAMA 2000;283(10):1293.

14. Mabasa VH, Malyuk DL, Tung A, Balen RM, Nicolls TR, Rahiman NL. Using clinical pharmacy support technicians to optimize pharmaceutical care in the intensive care unit. Can J Hosp Pharm 2010;63(1):41-45.

15. Lacaria K, Balen RM, Frighetto L, Lau TTY, Naumann TL, Jewesson PJ. Perceptions of the professional pharmacy services in a major Canadian hospital: a comparison of stakeholder groups. Longwoods Rev 2004;2(1):8-19.

16. Thompson CA. Legality of technicians' involvement in medication reconciliation not clear. Am J Health Syst Pharm 2009;66(5):433-434.

17. Harding J. Drug distribution systems. In: Babich M, Bussières JF, Hall KW, Harding J, Johnson N, Lefebvre P, et al., editors. Hospital pharmacy in Canada 2007/2008 annual report. Eli Lilly; 2008 [cited 2010 Jun 11]. p. 25-37. Available from: www.lillyhospitalsurvey.ca/ hpc2/content/2008_report/drugdistribution.pdf
18. Nahata MC. Clinical pharmacy: humble beginnings, extraordinary progress, and unprecedented opportunities [lecture]. In: Annual meeting of the American College of Clinical Pharmacy; 2009 Oct 18; Anaheim (CA). Lenexa (KS): American College of Clinical Pharmacy; 2009 [cited 2010 Jun 11]. Available from: www.accp.com/docs/ positions/misc/Nahata09PaulParkerMedal.pdf

Sean K Gorman, BSCPharm, ACPR, PharmD

Clinical Coordinator-Critical Care

\section{Shelley Heukshorst}

Clinical Support Pharmacy Technician

Pharmacy Department

Capital District Health Authority

Halifax, Nova Scotia

Dr Gorman is also an Associate Professor with the College of Pharmacy, Dalhousie University, Halifax, Nova Scotia.

\begin{tabular}{lll}
\multicolumn{4}{c}{ Advertisers } & \\
\hline & Ad Page & Prescribing Information \\
\hline ESBE Scientific / Corporate & 355 & - \\
\hline Hospira / Precedex & 352 & 396,397 \\
\hline Hospira / Corporate & 356 & - \\
\hline Pfizer / Fragmin & IBC & $398-401$ \\
\hline Pharmaceutical Partners of Canada / Corporate & IFC & - \\
\hline Pharmaceutical Partners of Canada / Corporate & OBC & - \\
\hline Sandoz / Corporate & 350 & - \\
\hline
\end{tabular}

